\title{
التحليل الجغرافي لنقل النفايات الصلبة في هحافظة واسط
}

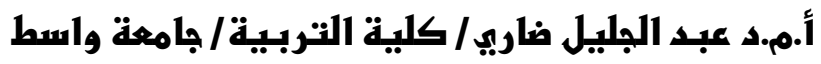

م. م باسم كاظم عباسر / كلية الآداب / جامعة واسط

|المستخاص

تُعدُّ در اسة نقل النفايات الصلبة وما يتعلق بها من مؤشرات لإدارة النفايات الصلبة من الدراسـات التي تستحق الاهتمـام و التوجـه نحو هـا كونهـا ظـاهرة مكانيـة تعكس اثار هـا على سـكان المـدن، وهـي ذات أهميـة خاصــة للجغر افيين و المخططين الحضريين ، إذ ان توزيع ألبات لنقل النفايات بشكل كفوء يساهم في تكوين بيئة صحية سليمة للمدينة ـ أظهرت الدراسـة تباين التوزيع النسبي للعاملين وللأليات في نقل النفايات الصلبة المتولدة في مدن المحافظة، وذلك نتيجة تباين عدد سكان كل وحدة ادارية وتباين عدد الاسر ومستو اها الاقتصادي وقدرتها الثر ائية وبالتالي ينعكس ذلك على تباين في كميات النفايات المتولدة

من المدن مما ادى الى تباين في عدد العاملين.

اهتمت الدر اسة على خدمة نقل النفايات الصلبة في مدن المحافظة، وتبين ان هذه الخدمة لا ترتقي الى المستوى المطلوب

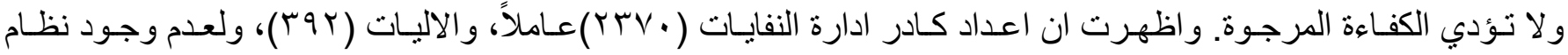

متكامل للتعامل مع النفايات الصلبة ، نتيجة قلة اعداد العاملين والآليات اثرت بشكل مباشر في تدني مستوى هذه الخدمات.

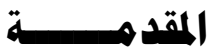

يعـد نقل النفايـات مـن المر احل المهمـة في ادارة النفايـات الصـلبة ، وتـأتي مباثـرة بعـد عمليـات الجمـع عندما تمـر المركبات سواء أكانت عربـات أم كابسـات للنفايـات من امـام المنـازل يقوم العمال بجمع النفايـات ثم تنقل تلك الى المحطات

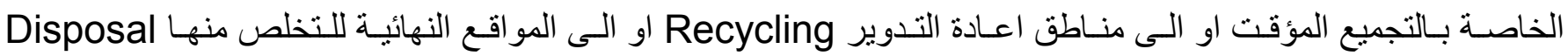
(المكبات). ويتم نقل النفايات عادة بوسـائط مختلفة من العربـة اليدويـة الى الاليـات الصغيرة و السـاحبات و الكابسـات الاعتياديـة و اللوريـات القلابـة الصـيرة و الكبيرة و المفتوحـة والمغلقـة والدنبر و غير ذلك ،وينتم النقل مـن خـلال العـاملين الذين يديرون ويحركون هذه الوسائل ، حيث ان لكل آلية كابسة نفايات (0) عمال تنظيف طبقا للمعيار عامل تنظيف ( ( ) واحد لكل ( . .0) نسمة، ولكل ( . .0م) من الثوارع الرئيسة والتجارية عامل التنظيف (1) واحد(i)، الا ان هذا المعيار غير ثابت وغير معدول بـه حالياً وذللك لان كميـة النفايـات مرتفعـة وتختلف بين منطقة واخرى كمـا تختلف كمياتها بين المنـاطق السكنية و المر اكز

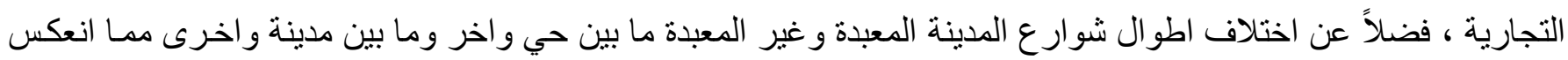
في عدم الاخذ في هذه المعايير. وتأتي أهميـة الدراسـة من حيث ان ادارة النفايـات الصلبة تعد مؤشر ا اساسـاً لمعرفـة تحضر المدن ونظافتها ، فبالتالي معرفة كفاءة هذه الخدمة المقدمة لسكان مدن المحافظة ، ومعرفة المشاكل التي تعيقها ، و التوصل الى

معالجات تحاول رفع كفاءة هذه الخدمات أدارة النفايات الصلبة بصورة اكثر فاعلية وحضارية.

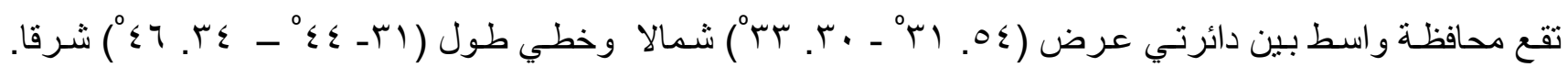
يحدها من الثمال ديالى ومن الثدمال الغربي محافظة بغداد ، ومن الغرب محافظتا بابل و القادسية ، ومن الجنوب محافظة ذي قـار ، ومـن الجنوب الثـرقي محافظـة ميسـان، ومـن الثـرق ايـران خريطـة ( () ـ ودر اسـة نقل النفايـات الصـلبة تعد مـن بين الدر اسات التي تستحق الاهتمام والتوجه نحو ها كونها تمثل المرحلة الثانية من مر احل ادارة النفايات الصلبة بعد مرحلة الجمع، 
لذا ينبغي على البلديات الاهتمام بها وتطوير هـا وتحسينها بمـا يلائم حاجة كل مدينـة لرفع كفاءتها المقدمة الى السكان ـ وهنـا سنتناول كيفية نقل النفايات الصلبة من قبل بلديات محافظة واسط هي كالاتي : خريطة (1) الوحدات الإدارية في محافظة واسط

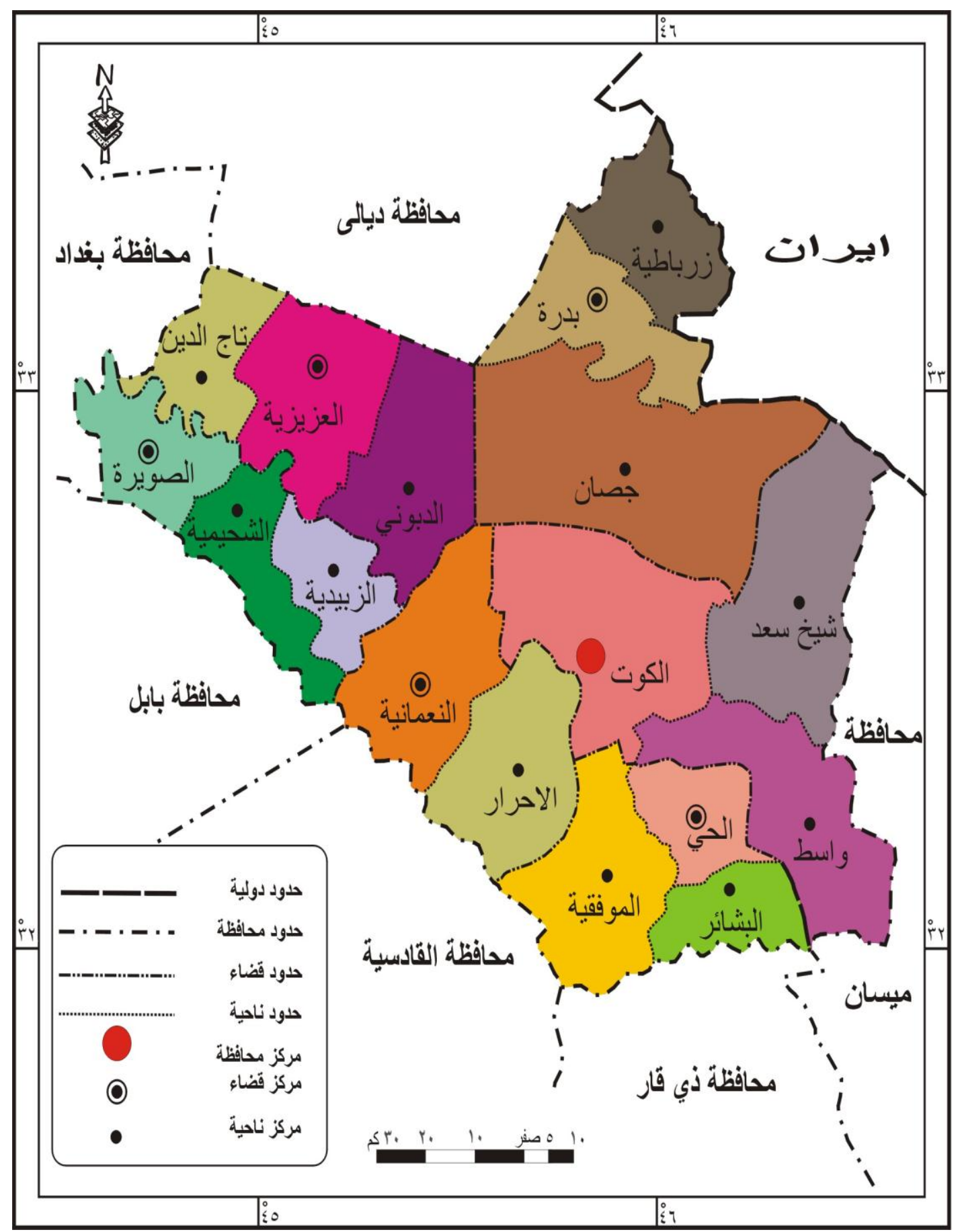

المصدر: الباحث بالاعتماد على : جمهورية العراق ، وزارة الموارد المائية، المديريـة العامـة للمساحة ، خريطة محافظة واسط الإدارية ، مقياس رسم

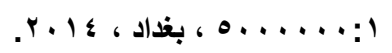

\section{اولاً: العاهلون في هبال رفع ونقل النفايات الصلبة :-}

يقوم العمال بجمع النفايات من امام المنازل ووضعها في الكابسة التي تسير ببطء وتحتوي هذه الكابسـات على جهاز لضغط ورص النفايات بمعدل ( ا-؟r) مرات لزيادة كمية النفايات المنقولة في المرة الواحدة(ii) ، كما تستطيع هذه الكابسـات نقل 


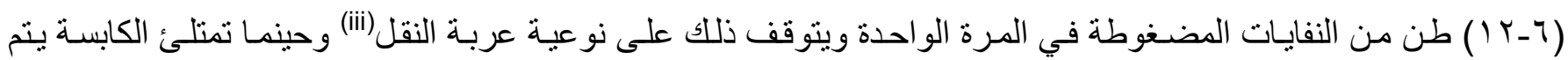
تفريغها في المكب ، وهي افضل و اسرع طريقة مستخدمة حالياً في مدن المحافظـة ، لكن في نفس الوقت هي طريقة مكلفة ومتعبة للعاملين(*) .و على الرغم من اتساع مدن محافظة واسط والتزايد المستمر في عدد سكانها كما يتو افد اعداد كبيرة من السكان على المناطق التجارية والسياحية يومياً لاسيما ايام الجمع و العطل وزيادة كميات النفايات المتولدة الا ان نسبة العمال

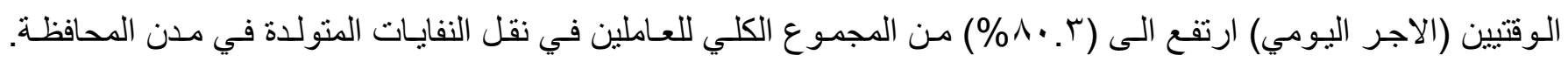
ويلاحظ من جدول ( ) تباين التوزيع النسبي للعاملين في نقل النفايـات المتولدة في مدن المحافظة ، وذللك نتيجة تباين عدد سكان كل وحدة ادارية وتباين عدد الاسر ومستو اها الاقتصسادي وقدرتها الثنر ائية وبالتـالي ينعكس ذلك على تباين في كميات النفايات المتولدة من المدن مما ادى الى تباين في عدد العاملين .

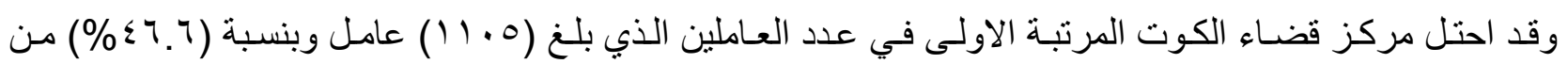

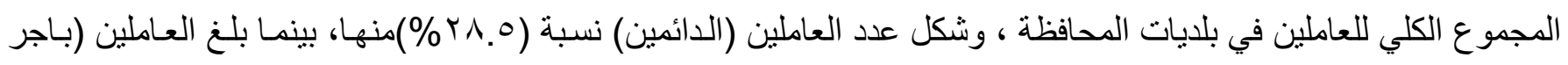
يومي) نسبة (9 §\%)منها، في حين لم تذكر أي نسبة للعاملين (بعقد حكومي) في مدينة الكوت ـ بينما جاء حضر ناحيـة زرباطية بالمرتبة الاخيرة حيث بلغ (9) عمال وبنسبة (0. • \%) من المجموع الكلي للعاملين في بلديات حضر المحافظة ، وقد

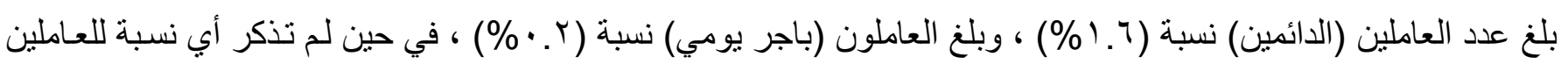
(بعقد حكومي) في حضر ناحية زرباطية.

اما باقي الوحدات الادارية الاخرى فتراوحت نسبها بين القيمتين المذكورتين ـ ويتبين من جدول ( ( ) ان نوع العمال العاملين في ادارة النفايات الصلبة في بلديات محافظة واسط تتباين نسبها بين وحدة اداريـة واخرى ، اذ استحوذ مركز قضـاء

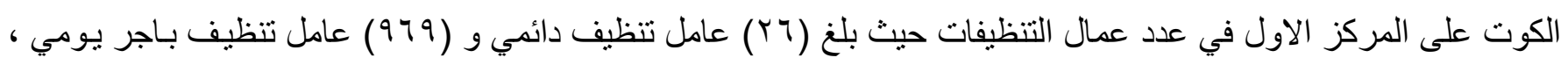

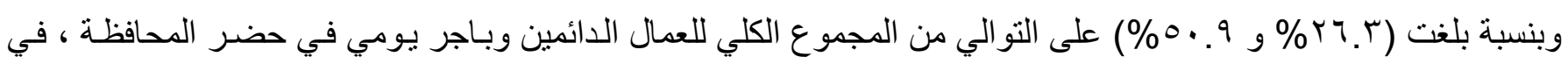

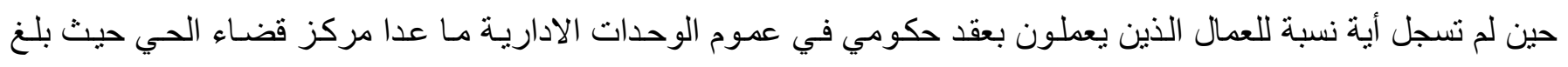
عددهم (T) عمال بنسبة بلغت ( · (\%) من المجموع الكلي للعاملين بعقد لدى بلديات المحافظة. وتبين مـن خـلال الدراسـة الميدانيـة ان اكثر مـن ( •0) عامـل تنظيف لبلديـة الكوت يعملون في الدوائر و المؤسسـات الحكومية غير تابعة لبلدية الكوت ، كـ(المحافظة والمجلس البلدي ، ومجلس القضاء الاعلى) فضلاً عن عملهم في تقديم الخدمـة لبيوت المسؤولين وقضاء كافة مستلزماهم البيتية والثخصية ، و هذا ما يسبب نقص في كادر جمع ونقل النفايات وبالتالي يؤثر ذلك في الخدمة المقدمة للمدينة او الحي . بينما استأثر كل من مركز قضاء بدرة وحضر ناحية زرباطية بالمركز الاخير بنسبة ( (\% ، ؟ · \%) ) على التوالي ،

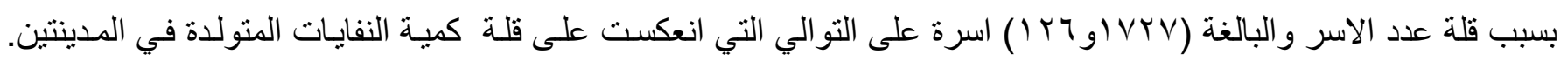
اما باقي الوحدات الادارية الاخرى فتر اوحت نسبها بين اعلى و ادنى قيمة في القيمتين المذكورتين . 


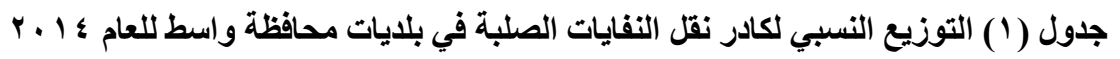

\begin{tabular}{|c|c|c|c|c|c|c|c|c|c|c|c|c|c|c|c|c|}
\hline \multirow{2}{*}{ الكلي } & \multicolumn{3}{|r|}{ المجموع } & \multicolumn{3}{|r|}{ اداري } & \multicolumn{3}{|r|}{ فني } & \multicolumn{3}{|c|}{ سائقي آليات } & \multicolumn{3}{|c|}{ عمال التنظيف } & \multirow[b]{2}{*}{ الادارية الوحـات } \\
\hline & عكوميـ & اجوميـيـر & دائمي & عقدمي & يوميـي & لدائمي & عكومي & يوميـيـر & دائمي & حكومي & اجوميـيـر & دائمي & عقميــ & يوميلير & لدائمي & \\
\hline$\leqslant 4.7$ & $\cdot$ & $\leqslant 9$ & $r \Lambda .0$ & . & Y.द & $r \Psi . r$ & $\cdot$ & $r \cdot . \varepsilon$ & $r 9.0$ & $\cdot$ & $r \leqslant .9$ & ro & . & 0.9 & Y.. & 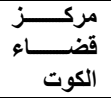 \\
\hline$r$ & $\cdot$ & $r . \wedge$ & 0.1 & $\cdot$ & $\cdot$ & $r Y . \wedge$ & $\cdot$ & $\cdot$ & Y.r & $\cdot$ & T.६ & Y.Y & $\cdot$ & T.A & 0.1 & واسطي \\
\hline r.A & $\cdot$ & $r . \wedge$ & r.0 & $\cdot$ & v. 1 & \&.A & $\cdot$ & $\cdot$ & Y.r & $\cdot$ & 9.7 & $\cdot$ & $\cdot$ & $r . r$ & v. 1 & شيخ سبد \\
\hline 8.4 & . & 8.5 & $\begin{array}{l}. \xi \\
\end{array}$ & $\cdot$ & v. 1 & 9.0 & $\cdot$ & . & \&.V & $\cdot$ & 11 & Y.Y & $\cdot$ & 7 & $1 \% .1$ & 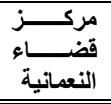 \\
\hline 1.9 & $\cdot$ & 1.5 & 9.7 & $\cdot$ & Y1.द & 9.0 & $\cdot$ & ¿.0 & v & $\cdot$ & $1 . \varepsilon$ & 8.7 & $\cdot$ & $1 . r$ & 0.1 & الاحريار \\
\hline 9.9 & Vo & 0.9 & $11 . r$ & 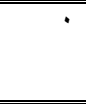 & $\cdot$ & $\cdot$ & $\cdot$ & $\cdot$ & \&.V & . & T.६ & $1 \pi$ & $1 \ldots$ & $1 \cdot . r$ & 10.4 & 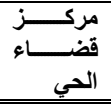 \\
\hline 1.9 & $\cdot$ & 1.0 & $r$ & $\cdot$ & $\cdot$ & $\cdot$ & $\cdot$ & $\cdot$ & r.r & $\cdot$ & ๕. 1 & 1.1 & $\cdot$ & 1.4 & $r$ & الموفية \\
\hline .97 & $\cdot$ & $\cdot . .^{r}$ & T.1 & $\cdot$ & $1 \leqslant . \%$ & $\cdot$ & $\cdot$ & $\cdot$ & $\mathrm{v}$ & $\cdot$ & $\cdot$ & $\begin{array}{l}. Y \\
\end{array}$ & $\cdot$ & $\cdot . .^{\top}$ & $r$ & النشائر \\
\hline$\overline{\Lambda .1}$ & $\cdot$ & $\overline{\Lambda . Y}$ & $\overline{\Lambda . Y}$ & . & $\frac{1.1}{1.1}$ & \&.1 & $\cdot$ & \&1 & \&.V & $\cdot$ & 9.7 & 11.0 & $\cdot$ & $\overline{v . r}$ & $\cdot$ & قالصويــــــــز \\
\hline ץ. & - & $r .0$ & 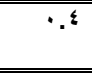 & $\cdot$ & $\cdot$ & $\cdot$ & . & - & T.r & $\cdot$ & r. & · & $\cdot$ & T. ${ }^{7}$ & . & الزيبيدية \\
\hline $1 . r$ & $\cdot$ & $\frac{1 . r}{1 . r}$ & 1.7 & & r1. & 9.0 & $\cdot$ & $\xi .0$ & r.r & $\cdot$ & 1.8 & 1.1 & $\cdot$ & 1 & $\cdot$ & الثنحيمية \\
\hline 8.1 & $\cdot$ & 7.1 & 0.9 & $\cdot$ & $\cdot$ & $\cdot$ & $\cdot$ & Y.r & T.r & 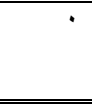 & 9.7 & r.r & . & 1 & 11.1 & 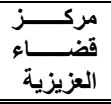 \\
\hline 4.7 & ro & \&.1 & V.A & & . & $\cdot$ & $\cdot$ & $\overline{r V . r}$ & $\mathrm{~V}$ & $\cdot$ & Y.V & 17.4 & $\cdot$ & T.V & $\bar{r}$ & الداحية تاج \\
\hline $1 . \varepsilon$ & . & $1 . \xi$ & r & & $\cdot$ & $\cdot$ & $\cdot$ & $\cdot$ & $\xi . V$ & $1 \ldots$ & Y.1 & 1.1 & $\cdot$ & $1 . \mathrm{V}$ & T & الداحيوني \\
\hline$\cdot .9$ & . & $\cdot .^{\wedge}$ & r & . & $\cdot$ & \&.^ & . & $\cdot$ & Y.r & $\cdot$ & $r .1$ & Y.Y & $\cdot$ & $\because \mathrm{V}$ & 1 & 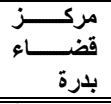 \\
\hline $1 . r$ & . & 1.1 & T.1 & & $\cdot$ & $\cdot$ & $\cdot$ & $\cdot$ & r.r & $\cdot$ & $\cdot v^{V}$ & 1.1 & $\cdot$ & 1.5 & 7.1 & نصاحئنـانة \\
\hline$\because 0$ & - & $\because Y$ & 1.7 & & & & $\cdot$ & $\cdot$ & T.r & $\cdot$ & $\because v$ & T.r & $\cdot$ & $\because{ }^{r}$ & $\cdot$ & ناحياطية \\
\hline$\%$ & - & $\% 1 \ldots$ & $\% 1 \ldots$ & & $\%$ & $\%$ & $\cdot$ & $\%$ & $\%$ & $\% 1 \ldots$ & $\% 1 \ldots$ & $\% 1 \ldots$ & $\% 1 \ldots$ & $\% 1 \ldots$ & $\begin{array}{r}1 \% \\
\% \\
\end{array}$ & المجموع \\
\hline
\end{tabular}

المصدر : الباحث بالاعتماد عل ملحق (1).

اما عمال سائقي أليات التنظيف فقد نـال مركز قضـاء الكوت المرتبة الاولى بواقع (ع V) سـائق مركبة ، منها (YT)

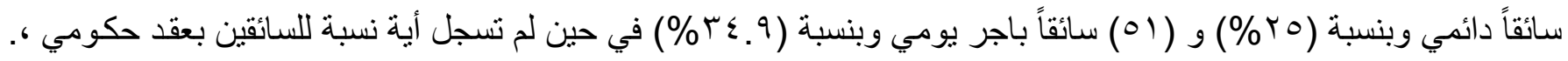
و هنا نلاحظ ان بلديـة مدينـة الكوت تعـاني من النقص في عدد سـائقي الآليات التي تستخدم لجمع ونقل النفايـات، اذ ان عدد

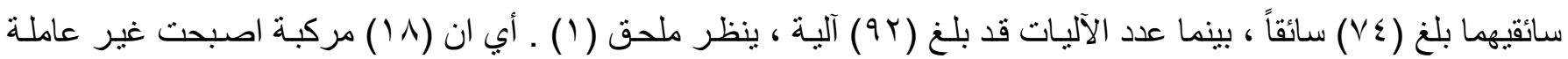
و غير فعالة في عملية ادارة النفايات خلال اليوم الواحد ، فعدد السائقين لا يسد الحاجة الفعلية لعدد الآليات، وبالتالي سيؤثر ذلك

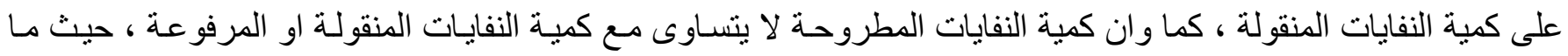
يقارب ( إ؟ب) طن/ يومياً من النفايات الصلبة تبقى مطروحة وغير مرفو عة من مدن واحياء مدينة الكوت وبالتالي هذه الكمية لها اثار سلبية على بيئة المدينة وتلوثها و على مظهر ها الجمالي .

بينما جاء حضر كل من ناحية الموفقية والثحيمية وجصـان بالمرتبـة الاخيرة بو اقع سـائق واحد دائمي وبنسبة ( ـ ( \%) لكل منها ، و ( ) سائق باجر يومي لكل من حضر ناحية جصان وزرباطية وبنسبة (V. • \%) من مجموع السـائقين بـاجر يومي 
في بلديات المحافظـة ، ولم يذكر أيـة نسبة للسـائقين بعقد حكومي .امـا بقية الوحدات الاداريـة فتراوحت نسبتها بين القيمتين المذكورتين. اما (الفنبين و الاداريين) فهي ايضاً نسبها متباينة بين الوحدات الاداريـة سواء أكانوا عمـال يوميين ام عمال بـأجر يومي. وباعتماد الدرجة المعيارية يمكن ان نميز من الجدول (Y) و الخريطة (Y) اربعة مستويات لكادر نقل النفايات الصلبة

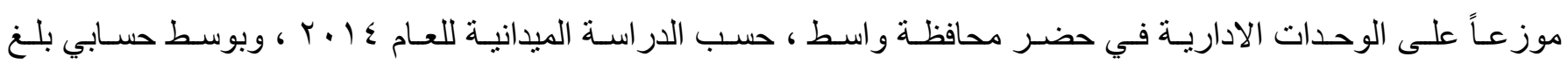

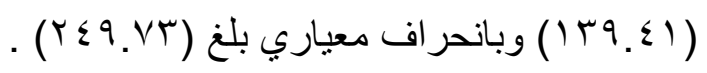

\section{المستوى الاول: بلغت الدرجة المعيارية (+•.أمأكثر)}

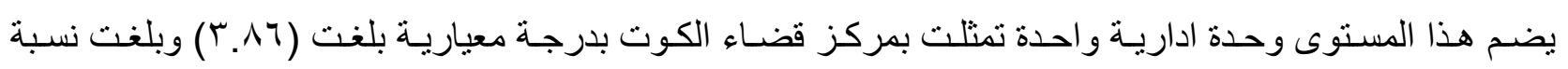
العاملين فيها (7 .7 ٪\%) من المجموع الكلي لكادر نقل النفايات في حضر محافظة واسط.

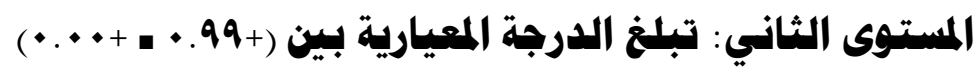

يوجد في هذا المستوى اربع وحدات ادارية هي (مركز قضـاء الحي ومركز قضـاء الصويرة ومركز قضـاء النعمانية

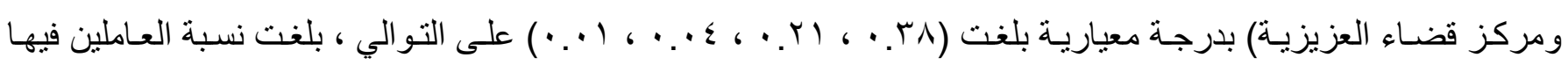

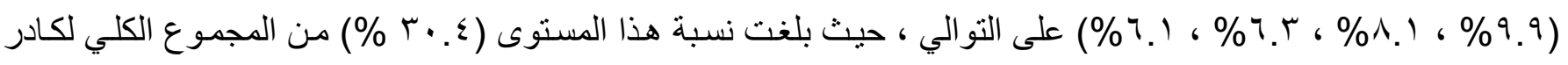
نقل النفايات في حضر المحافظة.

\section{المستوى الثالث: الذي تبلغ الدرجة المعيارية (-1 •. • -99. • )}

تظهر في هذا المستوى اثتنا عشر وحدة اداريـة تمثلت بحضر كل من (ناحية تـاج الدين ، وناحيـة الزبيديـة وناحيـة واسط وناحية شيخ سعد وناحية الاحرار وناحية الموفقية وناحية الدبوني وناحية جصان وناحية الشحيمية ومركز قضـاء بدرة وناحية

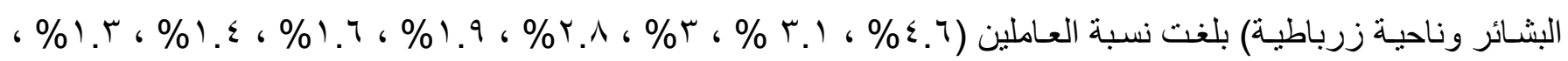

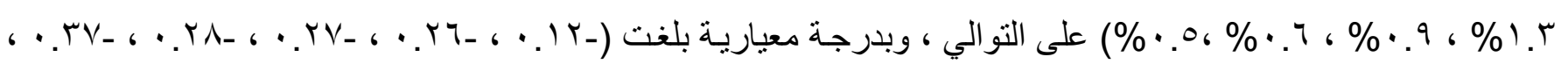

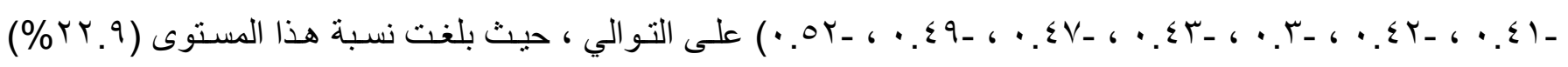
من المجموع الكلي لكادر نقل النفايات في حضر المحافظة. المستوى الرابع : تبلغ درجته المعيارية (-• . 1 فاقل) لم يظهر في هذا المستوى اي نسبة تذكر .

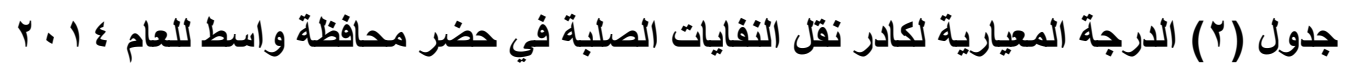

\begin{tabular}{|c|c|c|}
\hline الدرجة المعيارية & عدد كادر نقل النفايات & الوحدات الادارية \\
\hline$T . \wedge T$ & 11.0 & مركز قضاء الكوت \\
\hline$\cdot Y V_{-}$ & VI & ناحية و اسط \\
\hline$\because$ YA- & $7 \mathrm{~V}$ & ناحية شيخ سعد \\
\hline$\because \cdot \varepsilon$ & 10. & مركز قضاء النعمانية \\
\hline$\cdot r V_{-}$ & $\sum 7$ & ناحية الاحرار \\
\hline 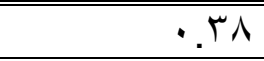 & rro & مركز قضاء الحي \\
\hline •.£1- & rV & ناحية الموفقية \\
\hline$\because \leqslant 9-$ & 10 & ناحية البشائر \\
\hline
\end{tabular}




\begin{tabular}{|c|c|c|}
\hline$\cdot . Y I$ & 194 & مركز قضـاء الصويرة \\
\hline . YY. & $V \varepsilon$ & ناحية الزبيدية \\
\hline$\cdot . \Sigma \mu_{-}$ & $r$. & ناحية الشحيمية \\
\hline. .1 & $1 \leqslant \varepsilon$ & مركز قضاء العزيزية \\
\hline $.1 T_{-}$ & $1 \cdot 1$ & ناحية تاج الدين \\
\hline$\because \leqslant Y_{-}$ & TE & ناحية الدبوني \\
\hline$\cdot . \Sigma V_{-}$ & YI & مركز قضاء بدرة \\
\hline$\cdot . \Sigma \mu_{-}$ & rI & ناحية جصان \\
\hline $.0 Y_{-}$ & 9 & ناحية زرباطية \\
\hline & rTV. & المجموع \\
\hline & $1 \% 9 . \Sigma 1$ & الوسط الحسابي \\
\hline & $r \leqslant 9 . V r$ & الانحر اف المعياري \\
\hline
\end{tabular}

المصدر : الباحث بالاعتماد على جدول (1).

خريطة (Y) التوزيع الجغرافي لكادر نقل النفايات الصلبة في

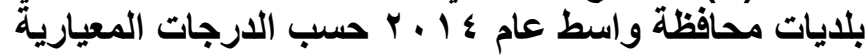

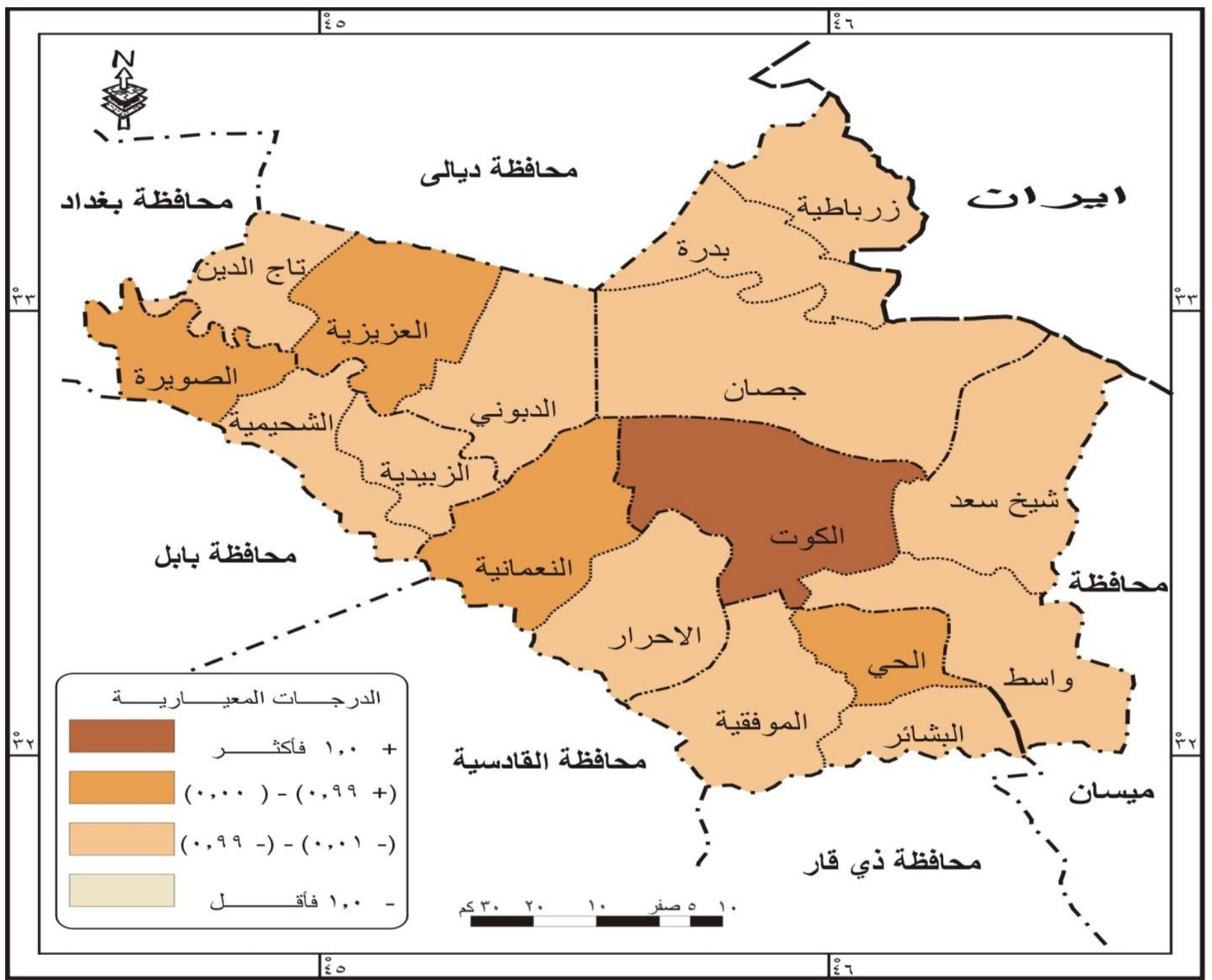

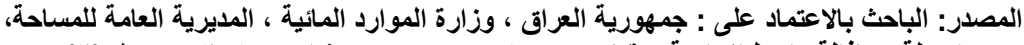

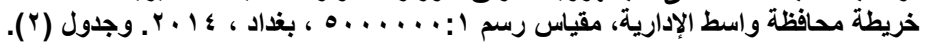




\section{ثانياً: الآليات المستخدهة بنقل النفايات الصلبة المتولدة في حضر هحافظة واسط.}

عند در اسة نظام نقل النفايـات الصلبة في أيـة مدينة نلاحظ بانهه هنـاك علافة وثيقة بين كفاءة نظامها و عدد الاليات المستخدمة ونوعها، لغرض الحصول على كفاءة جيدة لهذا العدد يجب معرفـة اعداد الاليات و انو اعها وصيانتها بصسورة مستمرة وكذلك استبدال المندثر منها، اذ ان أيـة نقص بهذه الجوانب يؤدي الى خلل في نظـام ادارة نفايات المدينـة وسنتنتاول الاليات المستخدمة في عملية نقل النفايات في حضر محافظة واسط.

أـ الكابسات: وتكون هذه الآليات عادة مغلقة ومزودة بجهاز لرص النفايات وتقليل حجمها لذللك فهي تجمع كميات كبيرة من النفايات وتكون اما ذات تحميل يدوي (manual) او ذات تحميل ميكانيكي (mechanical) وتمتاز هذه الانواع من الآليات

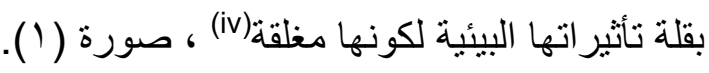
ب-الآليـات المكشـوفة : تستخدم هذه عندما يكون حجم النفايـات كبير نسبياً مثل نفايـات الحدائق والاثاث و الانقاض ، ويتم تحميلها اما يدوياً او عن طريق آليات اخرى كالثنفل ومن هذه الآليات الثـاحنات القلابـة و السـاحبات (التركترات) و غير هـا من

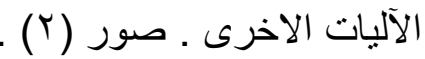
ج- آليات ملحقة: وتتألف من آلية رئيسة تسمى آلية الام مع عدد من آليات او العربـات الصغيرة التي تقوم بجمع النفايـات من

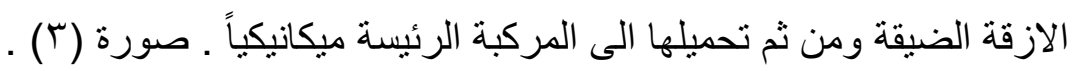
ومن خلال الدر اسة الميدانية اتضـح ان عدد الآليات الخاصـة بجمع ونقل ومعالجـة النفايـات الصلبة في حضر المحافظـة

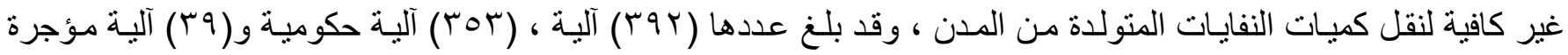
وتختلف هذه الآليات في سعة حمولتها كما ان اعدادها ينباين بين منطقة واخرى لأسباب عديدة اهمها عدد السكان في المنطقة السكنية وكمية النفايات المتولدة . اما كابسـات النفايات فقد بلغ عددها ؟1 ا كابسـة ، ويفترض ان هذا العدد كافٍٍ لجمع ونقل النفايـات الصلبة في مدن المحافظـة ، وذلك لان معيار وزارة البلديات و الاشـغال العامـة التي حددت ( • كابسـة نفايـات لكل

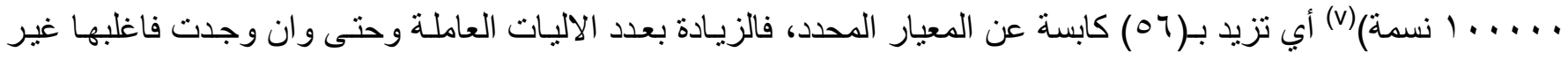
صالحة للعمل لتعرضها للعطل وقلة التخصيصات المالية لصيانتها ، و هذا ما سبب خلاً في تحقيق الخدمة بكفاءة عاليـة ، فضـلاً عن ان · r كابسة لا تحقق تقديم خدمة كافية لـ .... . . نسمة ، لذا يفترض على وزارة البلديات زيادة العدد بما يتتاسب مـع عدد السكان وكمية النفايات المتولدة لكل وحدة ادارية بعد إعادة النظر بالمعيار الذي حددته في هذا الخصوص. صورة (1) آلية جمع النفايات الصلبة (كابسة)

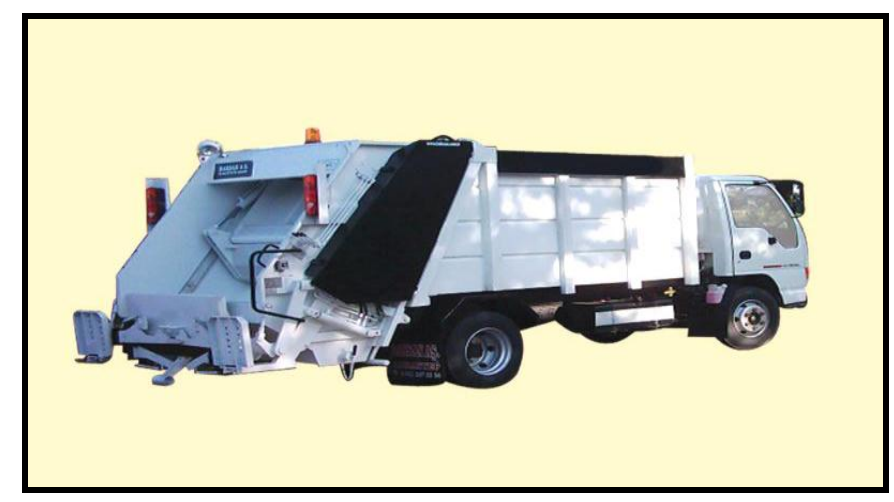

المصدر: الباحث بالاعتماد على وزارة الصناعة والمعادن،

شww.al-fedaa.com شركة الفداء للصناعات الهيدروليكية والمعدنية بالاعية ورلية 
صورة (ץ) نماذج للأليات المشوفة التي تستخدم في عملية جمع ونقل النفايات الصلبة

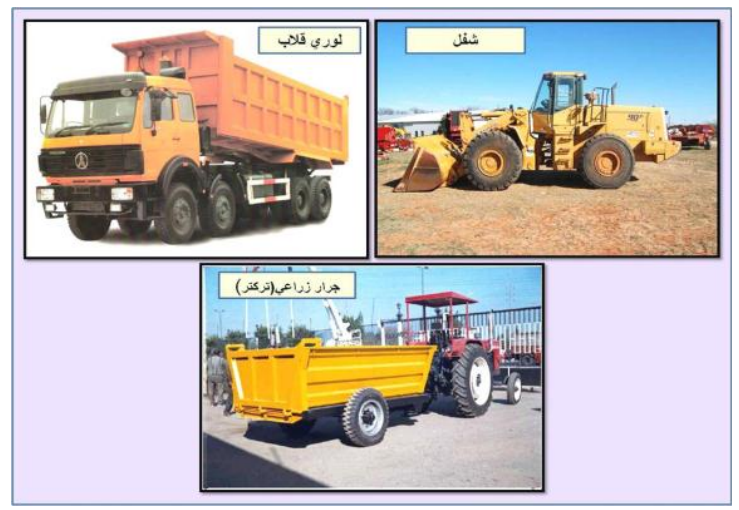

المصدر: الباحث بالاعتماد على مديرية بلدية الكوت ، شعبة الآليات ، ؛ 1 ـ. .

صورة (r) نماذج أليات وعربات صغير لجمع النفايات الصلبة في الازقة الضيقة

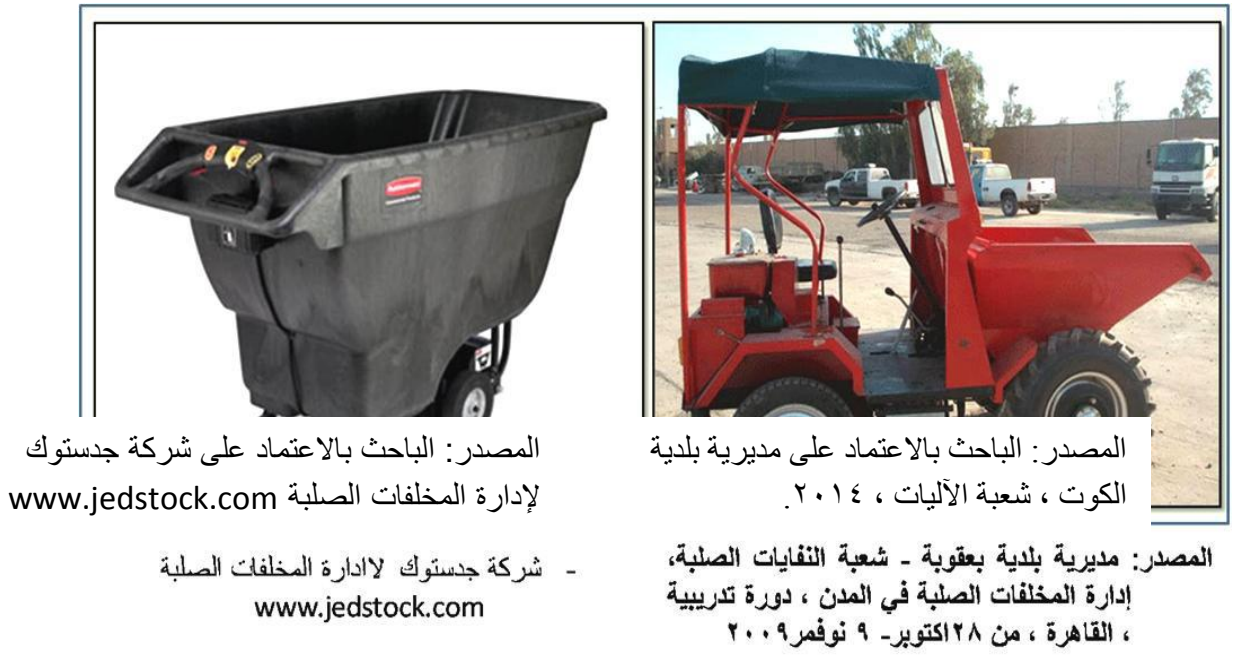

يلاحظ من جدول (r) ان التوزيع النسبي للآليات الخاصـة بجمع ونقل النفايـات الصلبة في حضر المحافظة تتباين نسبها بين مدينة واخرى، تختلف في انواعها وسعها حسب الوحدات الادارية ـ احتل مركز قضاء الكوت المرتبة الاولى في عدد الآليات

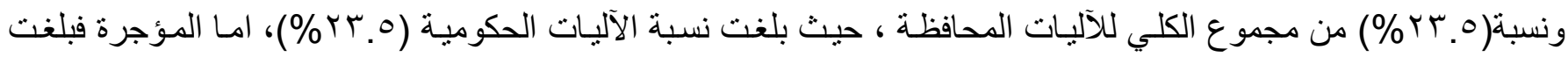

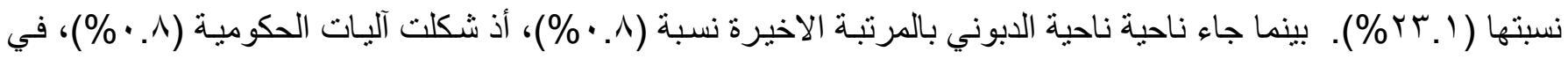
حين لم يذكر أي نسبة للآليات المؤجرة. بينما الوحدات الادارية الاخرى فتراوحت نسب قيمتها بين القيمتين المذكورثين. اما عدد الاليات حسب نوعيتها ، يتبين ان مركز قضـاء الكوت استحوذ على المركز الاول في نسب كابسات النفايات سعة (Y-Y طن)، فقد شكلت الحكوميـة منها نسبة (V. (Y\%\%)، امـا المؤجرة لم يسجل أب نسبة تذكر لها في حضر محافظة و اسط. بينما حصل على المركز الاخير حضر كل من ناحيتي الدبوني وزرباطية نسبة (1 ـ (\%) لكل منها من مجموع الكلي لكابسات النفايات في حضر المحافظة. امـا سـاحبات النفايـات سعة ( ( ـ طن) فقد احتل مركز قضـاء الصويرة المركز الاول بنسبة بلغت (9. • r \%) من مجموع الكلي لساحبات النفايات الحكومية في حضر المحافظة، في حين احتل مركز قضـاء الحي المركز الاول ونسبة بلغت (؟.بr\%) مـن مجموع الكلي لسـاحبات النفايـات المؤجرة في حضر المحافظـة. وذلك لان عدد الاليات التي توفرها البلدية في مدينة الحي لا يكفي لإدارة خدمة النفايات الصلبة ، لذا تلجأ بلدية المدينـة الاعتمـاد على الاليات من القطاع الخاص مقابل اجر معين من دون الاستناد الى قانون او ضو ابط معينة لتحديد كيفية تأجيرها وعدم استخدام المعايير 


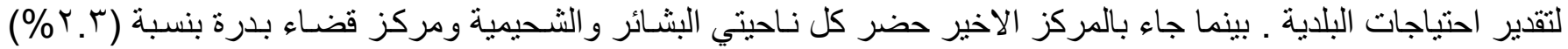
لكل منهما من مجموع الكلي لسـاحبات النفايـات الحكوميـة في حضر المحافظة. في حين لم تسجل أيـة نسبة تذكر في حضر نو احي كل مـن واسط و الزبيديـة والدبوني وزرباطيـة، امـا السـاحبات المؤجرة فكان ادناهـا في حضـر ناحيـة واسط وبنسبة

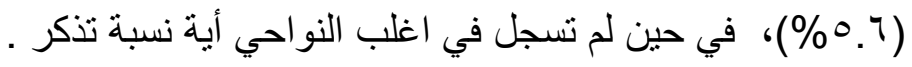

اما الدنبر سعة (1) طن، فقد تصدر مركز قضـاء الصويرة المركز الاول بنسبة (T. (ب\%\%) من مجموع الكلي لدنابر النفايات الحكومية ، وذلك بسبب وجود الاحياء والازقة الضيقة مما سـاعدت على تواجد الدنابر لسهولة الحركة داخل الاحياء الضيقة لجمع ونقل النفايات المتولدة من احياء المدينة. بينما جاء ادناها لكل من حضر ناحيـة شيخ سعد والموفقية وتـاج الدين ومركز قضاء بدرة ومركز قضـاء الحي وبنسبة بلغت (؟.0\%) ولكل منهم ، في حين لم ينت تسجيل أي نسبة تذكر للدنابر المؤجرة في حضر المحافظة ـ أمـا بقية الآليات و المركبـات المتمنلة بـ(الثفلات والقلابـات والكريدر و البلدوزر) فهي ايضـاً متباينة في نسبها سو اء أكانت حكومية ام مؤجرة بين الوحدات الادارية في حضر محافظة واسط.

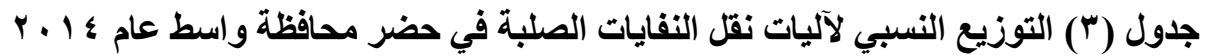

\begin{tabular}{|c|c|c|c|c|c|c|c|c|c|c|c|c|c|c|c|c|c|}
\hline \multirow[t]{2}{*}{ ع الكجليو } & \multicolumn{2}{|c|}{ المجموع } & \multicolumn{2}{|r|}{ بلاوزر } & \multicolumn{2}{|r|}{ كريدر } & \multicolumn{2}{|c|}{ 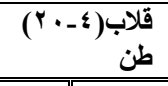 } & \multicolumn{2}{|r|}{ شفل } & \multicolumn{2}{|c|}{ طن طن (1) } & \multicolumn{2}{|c|}{ طن ساحبة (1 - ) } & \multicolumn{2}{|c|}{ 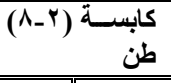 } & \multirow[b]{2}{*}{ الادارية } \\
\hline & مؤجرة & حكومي & مُوجر & حكومي & مُؤجر & حكومي & مؤجر & حكومي & مؤجرة & حكومي & مُؤجر & حكومي & مؤجرة & حكومي & مؤجر & حكومي & \\
\hline rr.o & Tr.I & Tr.O & - & YN.0 & . & $17 . \%$ & . & $1 \cdot . r$ & 74. $\mathrm{Y}$ & 17 & . & r.. & 19.2 & 11.7 & . & TI.V & الكركزت قضــاء \\
\hline r.A & 0.1 & T.O & . & - & . & . & . & 7.1 & . & $\varepsilon$ & . & . & 0.7 & . & . & Y.V & ناحية و واسط \\
\hline r. & $\cdot$ & T. & - & $\cdot$ & . & $\varepsilon . Y$ & . & \&.1 & . & $\varepsilon$ & $\cdot$ & 0.4 & . & $\varepsilon . V$ & . & Y.V & ناحعديـة شــيخ \\
\hline$\wedge . \wedge$ & Tr.I & $V . \varepsilon$ & - & . & . & ᄉ.r & . & r & . & $\varepsilon$ & $\cdot$ & . & ro & $9 . r$ & . & 9.7 & النعمانية قضــاء \\
\hline 纟.1 & . & $\leqslant 0$ & - & . & . & $\varepsilon . r$ & . & 7.1 & . & $\Lambda$ & - & . & . & v & . & r.^ & الاحرار \\
\hline 11 & $r \mu . r$ & 1.0 & . & $1 \varepsilon . \Gamma$ & $\cdot$ & А. ${ }^{r}$ & $\cdot$ & ๕.1 & $r \mu . r$ & $\varepsilon$ & $\cdot$ & 0.4 & rT.r & 11.7 & $\cdot$ & $9 . \%$ & الحركيز قضــاء \\
\hline$r . r$ & . & r. . & - & $1 \varepsilon . r$ & . & $\varepsilon . Y$ & . & r & . & $\varepsilon$ & . & 0.4 & . & $\varepsilon . V$ & . & r. & الموفيـية \\
\hline T.r & . & r.o & . & . & . & $\varepsilon . r$ & . & 7.1 & . & $\varepsilon$ & . & - & . & T.T & . & 1.7 & البشائير \\
\hline $11 . \%$ & $\cdot$ & 14 & . & $1 \varepsilon . r$ & $\cdot$ & 17.8 & $\cdot$ & $1 \cdot . r$ & $\cdot$ & $\Lambda$ & $\cdot$ & 11.7 & $\cdot$ & $r \cdot .9$ & $\cdot$ & $1 \cdot . r$ & قضاءعالصوير \\
\hline ๕. 1 & $\cdot$ & «.0 & . & $1 \leqslant . r$ & $\cdot$ & A.r & . & A.r & $\cdot$ & $\varepsilon$ & . & 0.4 & . & . & . & $r . \Lambda$ & ناحيبية \\
\hline 1.1 & . & r & . & . & . & $\varepsilon . Y$ & . & $r$ & . & $\varepsilon$ & . & . & . & r.r & . & 1.7 & الثحيمية \\
\hline 11 & $10 . \varepsilon$ & $1 . .0$ & . & $1 \varepsilon . r$ & $\cdot$ & \&. $r$ & . & $1 \leqslant . r$ & . & Ir & . & 10.1 & 17.8 & $1 \varepsilon$ & . & $\Lambda .7$ & العزيزية قضــاء \\
\hline$\varepsilon . \Gamma$ & . & $\varepsilon . \wedge$ & - & . & . & ᄉ.r & . & 7.1 & . & $\varepsilon$ & . & $0 . r$ & . & v & . & $r . \wedge$ & الدينيـة تــــاج \\
\hline$\cdot \wedge$ & . & $\cdot{ }^{\wedge}$ & - & - & $\cdot$ & $\cdot$ & $\cdot$ & . & . & $\varepsilon$ & $\cdot$ & $\cdot$ & $\cdot$ & $\cdot$ & $\cdot$ & 1.1 & 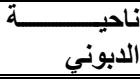 \\
\hline$\varepsilon . r$ & . & $\varepsilon . \wedge$ & - & . & $\cdot$ & A.r & . & $1 \cdot . r$ & . & 1 & $\cdot$ & $0 . r$ & $\cdot$ & T.T & $\cdot$ & r. & بركز قضساء \\
\hline 1.1 & 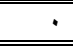 & $r$ & $\cdot$ & 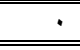 & 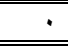 & 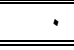 & 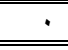 & $\varepsilon .1$ & . & $\varepsilon$ & 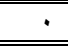 & 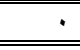 & 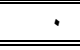 & r.r & 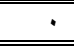 & 1.7 & ناحية جصان \\
\hline $1 . r$ & . & $1 . \varepsilon$ & - & - & . & - & . & ๕.1 & . & $\varepsilon$ & $\cdot$ & . & . & · & · & 1.1 & زناحياطية \\
\hline$\% 1 \ldots$ & $\begin{array}{r}1 \% \\
\% \\
\end{array}$ & $\begin{array}{r}1 \% \\
\% \\
\end{array}$ & & $\begin{array}{r}1 \% \\
\% \\
\end{array}$ & $\cdot$ & $\begin{array}{r}1 \% \\
\% \\
\end{array}$ & & $\begin{array}{r}1 \ldots \\
\% \\
\end{array}$ & $\begin{array}{r}1 \% \\
\% \\
\end{array}$ & $\begin{array}{r}1 \% \\
\% \\
\end{array}$ & $\cdot$ & $\begin{array}{r}1 \% \\
\% \\
\end{array}$ & $\begin{array}{r}1 \ldots \\
\% \\
\end{array}$ & $\begin{array}{r}1 \% \\
\% \\
\end{array}$ & $\cdot$ & $\begin{array}{r}1 \% \\
\% \\
\end{array}$ & المجموع \\
\hline
\end{tabular}

المصدر: الباحث بالاعتماد على ملحق (ץ) . 
وباستخدام الدرجة المعياريـة يمكن ان نميز من الجدول (ع) و الخريطة (r) اربعة مستويات للآليات بعلية نقل النفايات الصلبة في حضر محافظة واسط ، وذلك من خلال الوسط الحسابي الذي بلغ ( . بr) و الانحر اف المعياري (T9. (Y) .

\section{المستوى الاول : تبلغ درجته المعيارية (+•، الماكثر)}

يوجد في هذا المستوى وحدتان اداريتان وهما (مركز قضاء الكوت والمركز قضـاء الصويرة) بدرجة معياريـة بلغت

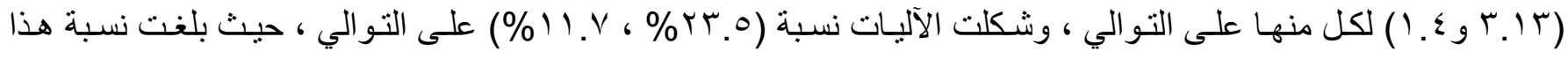
المستوى (r. .0 \%) من مجموع الكلي للآليات في حضر محافظة. و على الرغم من ارتفاع هذه النسبة الا ان عدد هذه الاليات

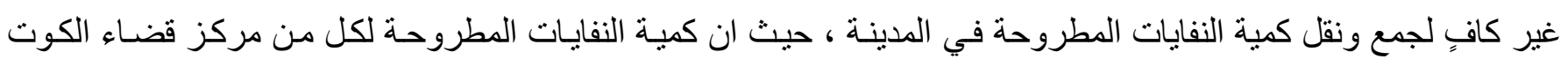

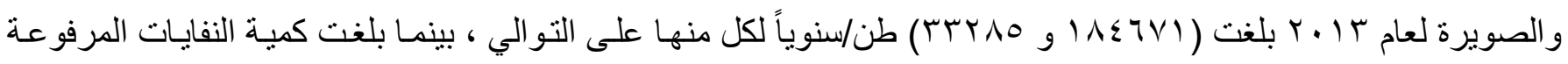

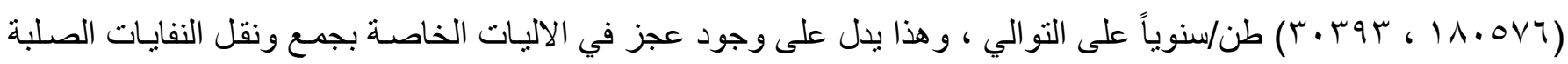
المطروحة.

\section{المستوى الثاني : تثزاوح الدرجة المعيارية بين (+99. • ـ +• •. • )}

تظهر فيه ثلاث وحدات ادارية تمثلت بـ(بمركز قضاء الحي ومركز قضاء العزيزية ومركز قضساء النعمانيـة) وبلغت

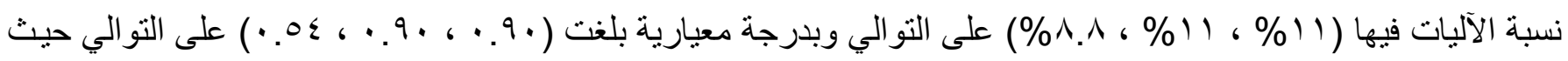

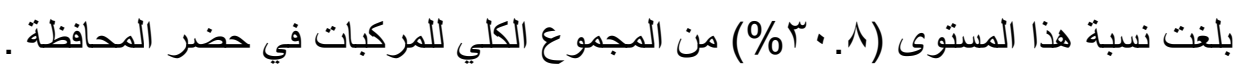

\section{المستوى الثالث : تتزاوح الدرجة المعيارية بين (-1 •. • ـ -99. •)}

يضـم هذا المستوى انثتى عشرة وحدة اداريـة تمثلت في حضر كل (ناحيـة تـاج الدين ومركز قضـاء بدرة وناحيـة الاحر ار وناحيـة الزبيديـة وناحية الموفقية وناحيـة شيخ سعد وناحيـة واسط وناحيـة البشائر وناحيـة الثيحمية وناحيـة جصـان وناحية زرباطية وناحية الدبوني) بدرجة معيارية بلغت (

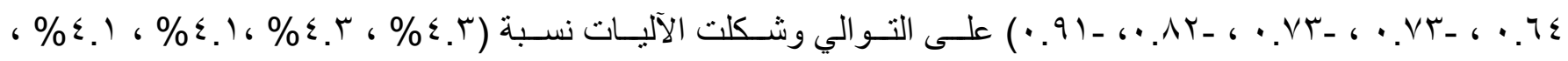

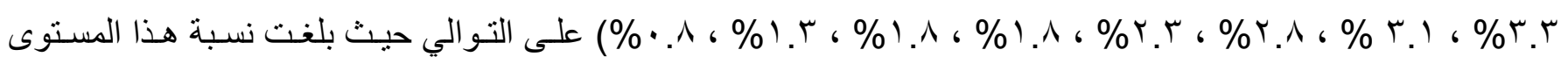

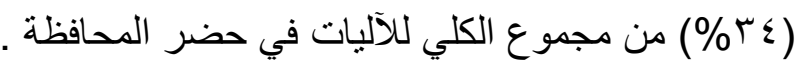

\section{المستوى الرابع : بلغت الدرجة المعيارية (-• .ا فاقل)}

يخلو من القيم

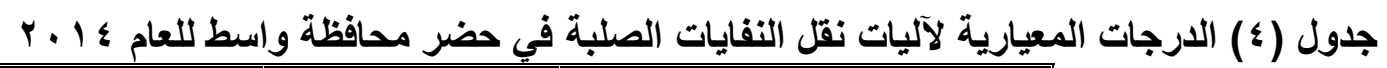

\begin{tabular}{|c|c|c|}
\hline الارجة المعيارية & عدد المركبات & الوحدات الادارية \\
\hline$r .1 r$ & 94 & مركز قضاء الكوت \\
\hline .00 & 11 & ناحية واسط \\
\hline$\therefore 0$ & Ir & ناحية شيخ سعد \\
\hline $.0 \leqslant$ & ro & مركز قضاء النعمانية \\
\hline$\cdot \mu_{Y}$ & 17 & ناحية الاحرار \\
\hline
\end{tabular}




\begin{tabular}{|c|c|c|}
\hline$\because 9$ & $\varepsilon r$ & مركز قضاء الحي \\
\hline$\cdot . \leqslant 0$ & 14 & ناحية الموفقية \\
\hline 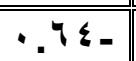 & 9 & ناحية البشائر \\
\hline $1 . \cdot \varepsilon$ & $\leqslant 7$ & مركز قضاء الصويرة \\
\hline$\cdot r_{H}$ & 17 & ناحية الزبيدية \\
\hline$\cdot V Y=$ & $V$ & ناحية الشحيمية \\
\hline$\because .9$. & $\varepsilon r$ & مركز قضاء العزيزية \\
\hline$\cdot Y V_{-}$ & IV & ناحية تاج الدين \\
\hline .911 & $r$ & ناحية الدبوني \\
\hline$\because Y V_{-}$ & iv & مركز قضاء بدرة \\
\hline$\because V Y-$ & $\mathrm{V}$ & ناحية جصان \\
\hline$\cdot \wedge Y_{-}$ & 0 & ناحية زرباطية \\
\hline & rqY & المجموع \\
\hline & rr.I & الوسط الحسابي \\
\hline & 71.97 & الاتحراف المعياري \\
\hline
\end{tabular}

المصدر : الباحث بالاعتماد على جلول (r) .

خريطة (ץ) التوزيع الجغرافي لآليات بنقل النفايات الصلبة في

حضر محافظة واسط عام \& 1 • ع حبب الارجات المعيارية

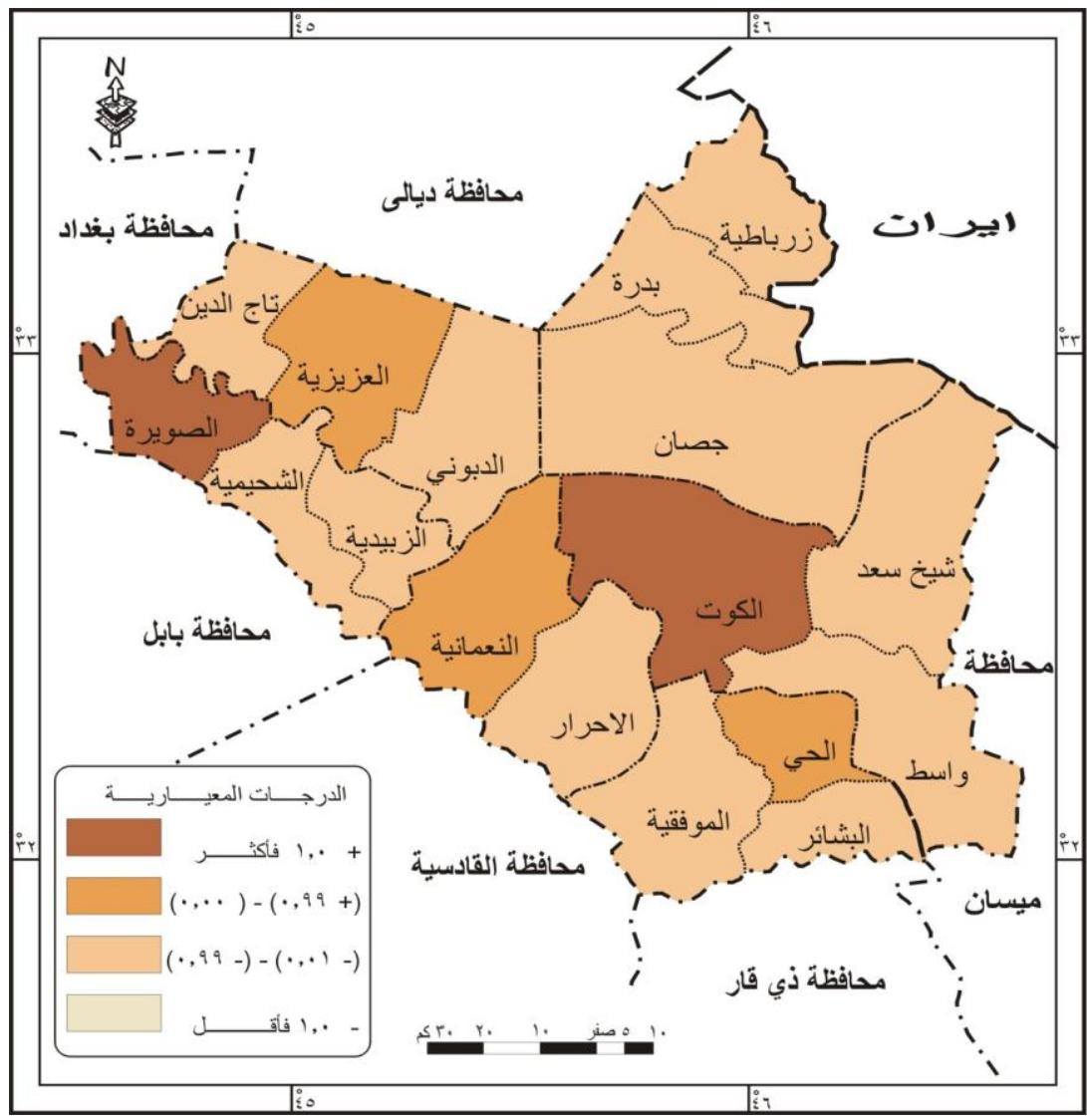

المصدر: الباحث بالاعتمـاد على : جمهوريـة العراق ، وزارة الموارد المائية ، المديريـة العامـة للمساحة ، خريطة محافظة واسط الإدارية ، مقياس رسم

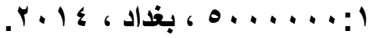


الاستتنتاجات

ا - وجدت الدر اسة تباين التوزيع النسبي للعاملين في نقل النفايات المتولدة في مدن المحافظـة ، وذلك نتيجة تباين عدد سكان كل وحدة ادارية وتباين عدد الاسر ومستو اها الاقتصادي وقدرتها الثر ائية وبالتالي ينعكس ذلك على تباين في كميات النفايات المتولدة من المدن مما ادى الى تباين في عدد العاملين .

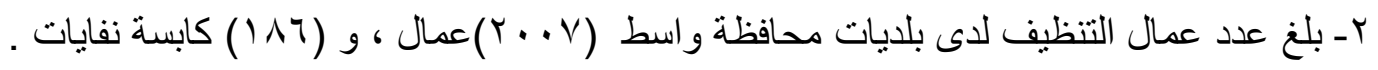

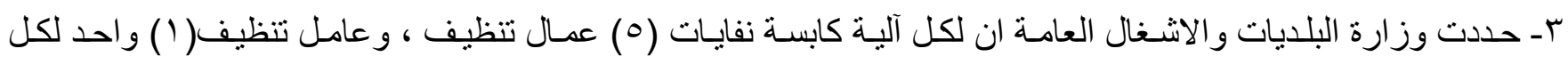
(0..) عـ اتضح ان عدد الآليات الخاصة بجمع ونقل ومعالجة النفايات الصلبة في حضر المحافظة غير كافية لنقل كميات النفايات

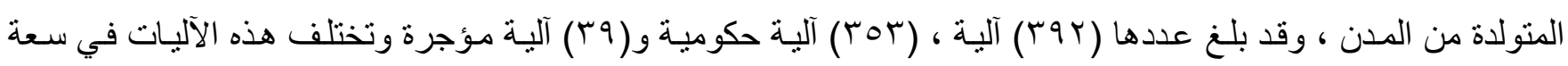
حمولتها كمـا ان اعدادها يتباين بين منطقة واخرى لأسباب عديدة اهمها عدد السكان في المنطقة السكنية وكميـة النفايـات المتولدة . هـ ت تنقل النفايات الصلبة الى مواقع المكبات دون معرفة نوعية وكميـة هذه النفايـات المنقولـة ، فضـلا عن عدم قيام بعمليات الفرز و الفصل و المعالجة الصحيحة و السليمة.

الاقتزحات

ا ـ نشر الوعي البيئي بين المواطنين بضرورة الحفاظ على البيئة من التلوث و الموارد الطبيعية من النفاذ. r - تشريع قو انين محلية خاصة بإدارة النفايات الصلبة وكيفية التعامل معها ، وبالتالي تكون غطاء قانوني وشر عي لكادر ادارة

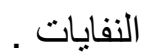

r- ضرورة استبدال عنوان الوظيفي لكادر ادارة النفايات الصلبة من عامل تنظيف الى موظف بيئي.

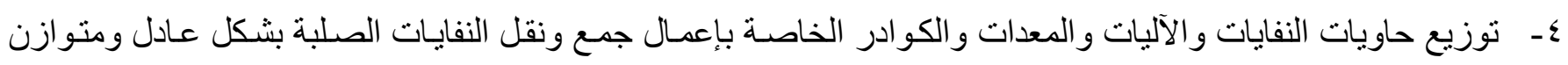
بين قطاعات المدينة حسب كميات النفايات المطروحة يومياء من كل قطاع بما يضمن تقديم خدمة أفضل لسكان المدينة . هـ إبلاغ المو اطنين تجنب طرح النفايات على جو انب الطرق و السـاحات المكثوفة وفرض غر امـات على المقصرين بهذا الجانب ، فضلا عن محاسبة النباثين الذين يعبثو ا في حاويات النفايات الموزعة بأحياء وقطاعات المدينة . .

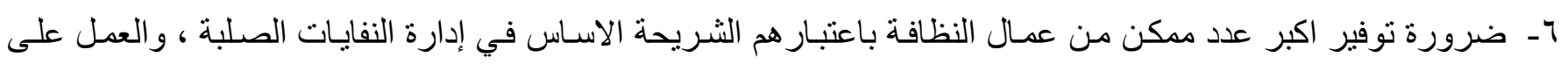
تو عيتهم بأهمية العمل الذي يقومون به ، وتدرييهم على أسـاليب الجمع و النقلي الآمنـة للنفايـات في المدينـة مـع تحسين الأجور المدفوعة لهم بما يتناسب حجم العمل الذي يئدونه .

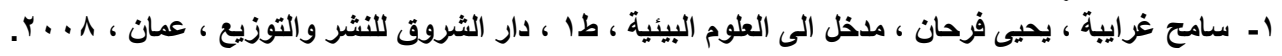
الب

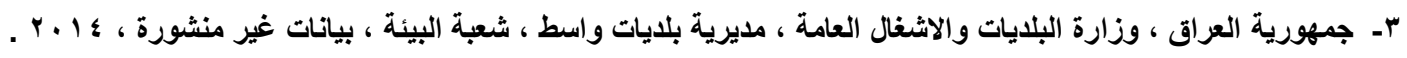

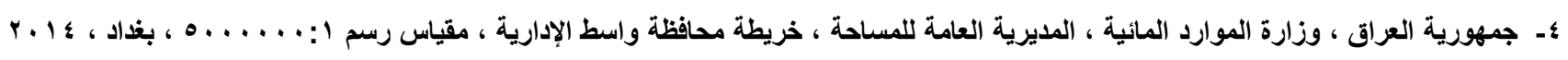

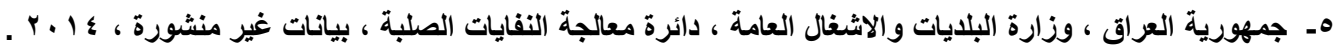

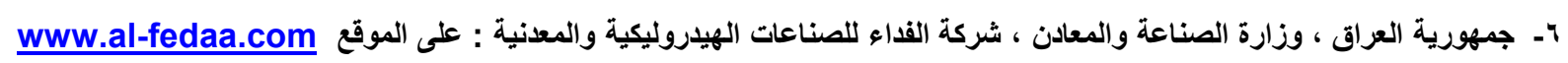

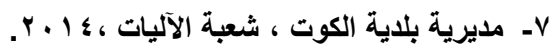




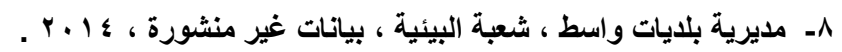

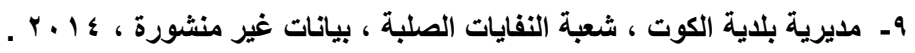

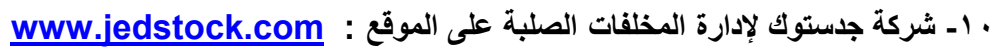

11- Koren Herman, Hand book of Environmental Health and safety, principles and practices, pergamon press New York , 1980 , p.36

$$
\text { ملحق (1) التوزيع العددي للآليات نقل النفايات الصلبة في حضر محافظة واسط عام ع ا ـ ب }
$$

\begin{tabular}{|c|c|c|c|c|c|c|c|c|c|c|c|c|c|c|c|c|c|}
\hline \multirow[t]{2}{*}{ ألكلي } & \multicolumn{2}{|r|}{ المجموع } & \multicolumn{2}{|r|}{ بلدوزر } & \multicolumn{2}{|r|}{ كريدر } & \multicolumn{2}{|c|}{ 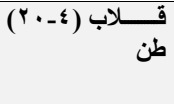 } & \multicolumn{2}{|r|}{ شغل } & \multicolumn{2}{|c|}{ دنبر (') طن } & \multicolumn{2}{|c|}{ ســاحبة نفايــات } & \multicolumn{2}{|c|}{ 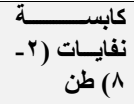 } & \multirow{2}{*}{ الوحدات الادارية } \\
\hline & مؤجرة & حكومي & مؤجرة & يكسو & جرة & ومه & مؤجرة & حيــوم & مؤجرة & يكسود & مؤجرة & حكومي & مؤجرة & يكسوه & جرة' & ويد & \\
\hline 94 & 9 & $\overline{N T}$ & . & $r$ & . & $\varepsilon$ & . & 0 & $r$ & $\varepsilon$ & . & $\varepsilon$ & $\mathrm{v}$ & 0 & . & 09 & مركز قضاء الكوت \\
\hline 11 & $\bar{T}$ & 9 & . & . & . & . & . & $r$ & $\cdot$ & 1 & . & . & r & . & . & 0 & باحية واسط \\
\hline IT & . & ir & . & . & . & 1 & . & r & $\cdot$ & 1 & . & 1 & . & r & . & 0 & ناحية شيخ سعد \\
\hline ro & 9 & ry & . & . & . & $r$ & . & 1 & . & 1 & - & . & 9 & $\varepsilon$ & . & 11 & مركز قضضاء النعماتية \\
\hline 17 & . & 17 & . & . & . & 1 & . & $r$ & . & $r$ & - & . & . & $r$ & . & v & ناحية الاحرار \\
\hline$\varepsilon r$ & ir & $r$. & . & 1 & . & r & . & $r$ & 1 & 1 & . & 1 & IT & 0 & . & 11 & مركز قضاء الحي \\
\hline$\pi$ & . & 14 & . & 1 & . & 1 & . & 1 & . & 1 & . & 1 & - & $\bar{T}$ & . & 7 & ناحية الموفقية \\
\hline 9 & $\cdot$ & 9 & . & . & . & 1 & . & $r$ & $\cdot$ & 1 & . & . & - & 1 & $\cdot$ & $r$ & ناحية البثائر \\
\hline$\leqslant 7$ & . & $\leqslant 7$ & . & 1 & . & $\varepsilon$ & . & 0 & $\cdot$ & $r$ & . & 7 & . & 9 & . & 19 & الصويرة \\
\hline 17 & . & 17 & . & 1 & . & $r$ & . & $\varepsilon$ & . & 1 & . & 1 & . & . & . & $\mathrm{v}$ & ناحية الزبيدية \\
\hline $\mathrm{v}$ & . & $\mathrm{v}$ & . & . & . & 1 & . & 1 & . & 1 & . & . & . & 1 & . & $r$ & ناحيةً الثحيمية \\
\hline$\varepsilon r$ & 7 & $r v$ & - & 1 & . & 1 & - & $\mathrm{v}$ & $\cdot$ & $r$ & . & $r$ & 7 & 7 & - & 17 & مركز قضاء العزيزية \\
\hline IV & . & iv & . & . & . & r & - & $r$ & . & 1 & . & 1 & - & $\bar{T}$ & . & $\mathrm{v}$ & ناحية تاج الاين \\
\hline$r$ & . & $r$ & . & . & . & . & . & . & . & 1 & - & . & . & . & . & r & ناحية الابوني \\
\hline IV & . & iv & . & . & . & $r$ & . & 0 & . & $r$ & . & 1 & - & 1 & . & 7 & مركز قضاء بدرة \\
\hline $\mathrm{v}$ & . & $\mathrm{v}$ & - & . & . & . & - & r & - & 1 & - & . & . & 1 & . & $r$ & ناحية جصان \\
\hline o & - & o & - & . & . & . & . & r & . & 1 & . & . & . & . & . & $r$ & ناحية زرباطية \\
\hline rar & rq & ror & . & $\mathrm{v}$ & . & $r \varepsilon$ & . & ₹9 & $r$ & ro & . & 19 & $r 4$ & $\varepsilon r$ & $\cdot$ & 11 & المجموع \\
\hline
\end{tabular}

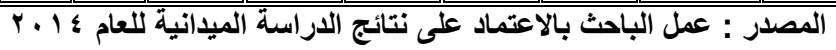

ملحق (Y) التوزيع العددي لكادر ادارة النفايات الصلبة في حضر محافظة واسط للعام ؟ 1 ـ ب

\begin{tabular}{|c|c|c|c|c|c|c|c|c|c|c|c|c|c|c|c|c|}
\hline \multirow[t]{2}{*}{ مـج الكلي } & \multicolumn{3}{|c|}{ المجموع } & \multicolumn{3}{|r|}{ الداري } & \multicolumn{3}{|r|}{ فني } & \multicolumn{3}{|c|}{ سائق التنظيفات } & \multicolumn{3}{|c|}{ عمال التنظيفات } & \multirow{2}{*}{ الادارية اللــات } \\
\hline & عقومي & اجر يومي & دائمي & عكميـ & يومي & دائمي & عكومي & يومي & دائمي & عكومي & اجوميـــ & يانس & عكومي & يومي & دائمي & \\
\hline 11.0 & ". & $1 . r Y$ & $V^{\mu}$ & . & 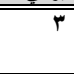 & $\mathrm{v}$ & . & 9 & IV & , & 01 & $r r$ & . & 979 & Y4 & الكوتز قضساء \\
\hline 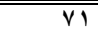 & . & 01 & $1 \%$ & . & . & 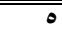 & . & $\cdot$ & $T$ & $\cdot$ & $\overline{0}$ & $\bar{r}$ & $\cdot$ & OY & 0 & ناحية واسط \\
\hline TV & . & 01 & 9 & $\cdot$ & $\cdot$ & 0 & . & $\cdot$ & $\overline{T 1}$ & $\cdot$ & $1 \leqslant$ & . & . & $\varepsilon r$ & $\overline{v V}$ & سنديـة شـيخ \\
\hline 10. & . & $1 \pi 1$ & 19 & (". & 1 & 1 & . & . & $\bar{T}$ & . & 17 & $\bar{r}$ & ?. & $11 \leqslant$ & $1 \pi$ & النعمانية قضاء \\
\hline$\$ 4$ & . & rq & IV & . & $T$ & $\bar{r}$ & . & $r$ & 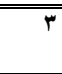 & $\cdot$ & $\overline{\bar{Y}}$ & $\overline{v V}$ & $\cdot$ & $\overline{T Y Y}$ & 0 & 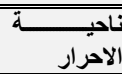 \\
\hline Tro & $\overline{79}$ & 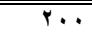 & rq & $\cdot$ & $\bar{\mu}$ & $\overline{T r}$ & . & . & $\overline{\bar{r}}$ & . & 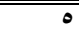 & $\overline{T I T}$ & $\overline{79}$ & 190 & 10 & مركز قضساء \\
\hline
\end{tabular}




\begin{tabular}{|c|c|c|c|c|c|c|c|c|c|c|c|c|c|c|c|c|}
\hline & & & & & & & & & & & & & & & & الحي \\
\hline$r v$ & 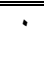 & $\overline{r r}$ & 0 &. & . & . & . & 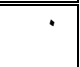 & $\bar{~}$ & . & $\bar{~} 1$ & 1 & . & 47 & $\bar{r}$ & الموفيقة \\
\hline 10 & . & $\bar{v}$ & $\overline{\Lambda \Lambda}$ & $\cdot$ & . & . & $\cdot$ & . & $\bar{r}$ & $\cdot$ & $\cdot$ & 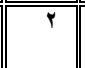 & . & 0 & $\bar{\mu}$ & 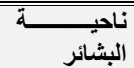 \\
\hline 194 & · & IVY & ru & 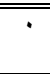 & $\bar{r}$ & ". & . & 11 & $\overline{T r}$ & 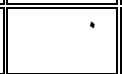 & $1 \varepsilon$ & IV & 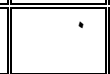 & 149 & $\overline{c .}$ & الصوكزيرة قضـاء \\
\hline$V \xi$ & $\bar{l}$ & $\overline{V r}$ & 7 & . & 1 & 1 & 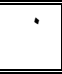 & $\bar{l}$ & 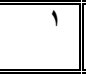 & $\bar{l}$ & 0 & . & $\bar{l}$ & 71 & . & الزاحيدية \\
\hline r. & . & 47 & $\xi$ & . & . & . & 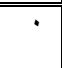 & $\bar{r}$ & 1 & $\bar{l}$ & $\bar{r}$ & 1 & $\overline{.}$ & 19 & . & الثنحيمية \\
\hline $1 \leqslant \xi$ & · & $1 \times 9$ & 10 &. & . & $\overline{T r}$ & $\cdot$ & $\overline{11}$ & 1 & $\cdot$ & $1 \varepsilon$ & $\overline{\Gamma r}$ &. & $11 \varepsilon$ & 11 & مركزيزية قضساء \\
\hline 1.1 & $\overline{T r}$ & 114 & $\overline{r .}$ &. & $\bar{~}$ & 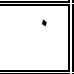 & $\bar{~}$ & $\overline{T Y}$ & $\bar{\Gamma}$ & $\bar{T}$ & $\overline{\varepsilon \xi}$ & 10 & $\bar{~}$ & V. & $\overline{T r}$ & الداحيـة تـاج \\
\hline$\overline{~ r \varepsilon}$ & · & rq & 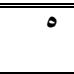 & $\bar{l}$ & $\bar{~} \bar{c}$ & 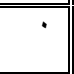 & 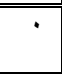 & $\bar{~} \bar{c}$ & $\overline{Y r}$ & 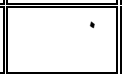 & $\bar{r}$ & 1 & $\bar{~}$ & $\overline{Y 4}$ & $\overline{T r}$ & 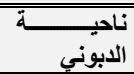 \\
\hline rI & $\overline{c .}$ & 17 & $\overline{0}$ & $\bar{l}$ & $\bar{l}$ & 1 & $\overline{.}$ & . & $\overline{11}$ & $\bar{l}$ & $\bar{r}$ & $\overline{T r}$ & . & $1 \%$ & $\overline{~ T 1}$ & بركزة قضضـاء \\
\hline r1 & . & $\overline{Y r T}$ & $\overline{\bar{\Lambda}}$ & $\bar{~} \bar{c}$ & $\bar{~}$ & $\cdot$ & $\cdot$ & $\bar{~} \bar{c}$ & $\overline{\overline{1}}$ & $\bar{~} \bar{c}$ & $\bar{~}$ & $\bar{~} \overline{1}$ & $\bar{~}$ & $\overline{P Y Y}$ & $\overline{\mid c 1}$ & نصاحنين \\
\hline 9 & . & 0 & $\xi$ & . & $\bar{~}$ & . &. & $\bar{~}$ & 1 & . & 1 & $\overline{l r}$ & . & $\xi$ & 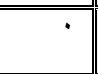 & زربياطية \\
\hline$\overline{r r V .}$ & $\bar{~} \bar{\Lambda}$ & r1. & YOY & $\bar{l}$ & $1 \varepsilon$ & $\overline{r 1}$ & $\overline{l .}$ & «ई & 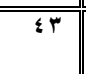 & $\bar{r}$ & $1 \leqslant 7$ & 94 & 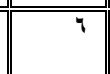 & 19. & 99 & المجموع \\
\hline
\end{tabular}

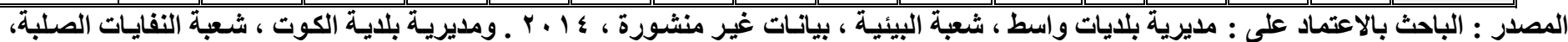

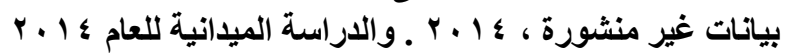

